\title{
ANCIENT PERSPECTIVES: MAPS AND THEIR PLACE IN MESOPOTAMIA, EGYPT, GREECE, AND ROME
}

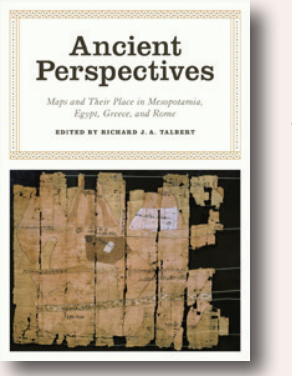

Edited by Richard J. A. Talbert.

The University of Chicago Press, 2012.

280 pages, 9 color plates, 82 halftones, 34 line drawings. $\$ 65.00$, cloth.

ISBN: 978-0-226-78937-8

Review by: Robert Cioffi, Bard University

Cartography has a long and diverse history, at once scientific, artistic, political, and social. It is precisely this history that forms the subject of the seven essays in Ancient Perspectives, the most recent volume from the Kenneth Nebenzahl, Jr., Lectures in the History of Cartography series. First delivered in November 2007 at the Newberry Library in Chicago, these lectures marked the twentieth anniversary of the first volume of the monumental History of Cartography, edited by J. B. Harley and David Woodward. Now published together in 2012, they seek to build upon the groundbreaking work of Harley and Woodward by reevaluating our understanding of ancient cartography in light of the scholarly developments of the past quarter century.

Ancient Perspectives spans some two and half millennia and four cultural contexts: Mesopotamia, Egypt, Greece, and Rome. The Classical world, which is the focus of five of the seven contributions, remains front and center, but, by combining the study of the Greco-Roman context with other related ancient cultures, Talbert's volume stands out from other recent contributions to the history of cartography. While it is not light reading, Ancient Perspectives has embraced its mission to make each contribution accessible to non-specialists in other fields. Almost all ancient terms have been translated, and readers will be pleased by the generous supply of maps, diagrams, photographs, and color plates. Contributors tend to stick to well-established consensus on most points of interpretation. As a result, the volume rarely engages with the nexus of theoretical approaches from disciplines such as urban studies, anthropology, and cultural geography that have come to characterize the "spatial turn" in the study of the ancient world. Contributors have preferred instead to collect, organize, and present ancient evidence.

What, then, counted as a map in antiquity? In Classical Latin mappa was the word for a napkin. Quite apart from the challenge of distinguishing dirty linen from cartography, the difficulty of defining a map is compounded by the absence of unambiguous ancient terminology for one. Contributors to Ancient Perspectives have operated with broad definitions to include building plans, charts of the heavens, instructions for constructing a map, and even textual representations of the world. While strict cartographic constructionists might balk, the advantage of casting such a wide net is that it shows the pervasive influence of what might be termed "cartographic thinking": maps are shown to be deeply intertwined with all aspects of ancient society.

Mesopotamia offers both the earliest examples of historical maps and some of the most plentiful and diverse cartographic traditions. In her chapter, "The Expression of Terrestrial and Celestial Order in Ancient Mesopotamia," Francesca Rochberg skillfully navigates this rich material, tracing the representation of space from the home to the cosmos. The majority of her chapter organizes cuneiform maps by topic (house plans, temple plans, field plans and cadastral surveys, city maps, regional maps, world maps, and the divine celestial landscape); this organization reflects her observation that there is "no coherent tradition" of cuneiform cartography (13). Throughout, Rochberg highlights the broader significances of spatial representation, concluding: "Various orders of power are implicit in the expression of these aspects of order in the environment. Administrative and economic powers support, or even require, the making of maps, as well as determining overtly the topographies that maps depict" (43). Her dense chapter, laden with examples, allows little room for detailed analysis of these various orders of power, but it provides the reader judicious guidance for further exploration 
and it presents a sophisticated, thoughtful, and reliable introduction to a fascinating body of ancient material. ${ }^{1}$

If Mesopotamia offers an overabundance of maps, there are far fewer examples from Egypt. David O'Connor's chapter, "From Topography to Cosmos: Ancient Egypt's Multiple Maps," suggests that the paucity of our evidence can be best explained by archaeologists' focus on excavating temples rather than administrative centers. Through an analysis of "maplike" artifacts, he emphasizes the pervasiveness of cartographic thinking in Egyptian art and text, ranging from the "world map" of Seti I (ca. 12901279) from the Karnak temple at Thebes, which depicts the Pharaoh smiting foreign foes, to the vignettes of the "Book of the Fayum," which encode the region's geography, cosmography, and sacred landscape. The connections between cartography and art can also be seen in the only extant map from Pharaonic Egypt. Probably drawn by the scribe Amenakhte in the $12^{\text {th }}$ century BCE, the socalled Turin Papyrus Map depicts the Wadi Hammamat, a riverbed route that connected the Nile Valley to the Red Sea. With remarkable precision, the map blends schematic and pictorial representations of the landscape, illustrated mountains, quarried bekhen-stone blocks, and the pebbled surface of the wadi bed. Despite the scarcity of extant maps, this chapter elucidates rich connections between cartography, texts, and religious art in ancient Egypt and it shows how deeply mapping was integrated with the rest of Egyptian culture.

Two closely linked chapters examine the traditions of Greek world mapping. Georgia L. Irby's "Mapping the World: Greek Initiatives from Homer to Eratosthenes," does not, despite its title, feature any ancient maps. She cautions: "We cannot know how many Greek maps were produced, or what exactly their content and purpose may have been. The different materials on which they were presented have rarely survived" (84). Instead, she traces the development of Greek cartographic thinking from Homer to the Hellenistic period, emphasizing the ideological implications of the study of geography in ancient Greece and the tension between empirical and philosophical bases for cartography. Her account points to two major catalysts for Greek cartographic revolutions: first, scientific thinkers from Miletus, whose influence reverberates especially in

1. Readers should be aware, as Leif Isaken has pointed out in a review published online in the American Journal of Archaeology 117.4 (2013), that an important recent article by Stephanie Meece in Anatolian Studies 56 (2006), 1-16 has reinterpreted the wall painting from Çatal Hüyük, which Rochberg identifies as a map (10-11), as an image of leopard. fifth-century Athens, and, second, Alexander the Great, whose campaigns fundamentally altered Greek views of the known world. The chapter culminates in Eratosthenes' measurement and mapping of the earth—the "acme" of Greek theoretical cartography (100)—and Hipparchus' criticisms of his methodologies and data. Irby's contribution traces the development of Greek cartography through an impressive range of sources and serves as a useful reference. Its heavy focus on summarizing sources and reconstructing their maps, however, leaves less time for exploring some of the most interesting questions it poses, such as the way in which "maps are an important expression of Greek culture” (105).

The second chapter on Greek cartography, Alexander Jones's "Ptolemy's Geography: Mapmaking and the Scientific Enterprise," is much more narrowly focused. A second-century CE text written in Greek, Ptolemy's Geography may not have included a map, but it certainly provided its readers with detailed instructions on how to make one. Jones examines and explains with remarkably clarity the "theoretical presuppositions" that lie behind this highly technical work, as he situates it in its intellectual context. Reading the Geography in dialogue with Ptolemy's other works, he focuses particularly on Ptolemy's epistemology and relationship to his predecessors. According to Jones, although Ptolemy vociferously criticized the data collection of his forerunner Marinus, his coordinate system for plotting the world was fundamentally agnostic about what it represented and the resulting map was "unpolitical" (125). He writes: "Strikingly, Ptolemy does not give the slightest indication that there exists such an entity as the Roman empire. . . The center of the map is not Rome or Alexandria, but the Persian Gulf" (125). While Jones is certainly right to point to Ptolemy's independence from the Roman Weltanschauung, even a decision not to acquiesce to Rome's world view could be interpreted as an act of resistance (think of Galileo). In fact, Ptolemy's decentering of the eternal city might be understood as running parallel to Rome's absence in other Greek authors of the second century CE. This thought-provoking chapter is highly recommended for anyone studying Ptolemy's Geography.

Michael Lewis's chapter, "Greek and Roman Surveying and Surveying Instruments," builds upon his 2001 book Surveying Instruments of Greece and Rome (Cambridge). Combining experimental archaeology with close reading of ancient sources, Lewis reconstructs the instruments and 
methodologies of ancient surveying and engineering, by means of which the Romans were able to record and transform their landscape. He demonstrates that Greek surveying was primarily accomplished by the dioptra, a circular instrument that could be used both vertically and horizontally. Roman surveyors had a more sophisticated toolkit, including the libra, which Lewis argues was a highly precise balance equal in precision to a modern level. His chapter concludes with a series of case studies, which suggest how Greeks and Romans might have employed such tools to construct roads, aqueducts, and tunnels. This chapter crosses into a world of engineering where few Classicists have dared to tread and it provides us with a much clearer picture of the complexities and challenges of Greek and Roman construction projects. Lewis is to be commended on making such a technical subject so accessible.

Richard J. A. Talbert's chapter on Roman cartography, "Urbs Roma to Orbis Romanus: Roman Mapping on the Grand Scale," focuses on monumental cartographic projects and their relationship to Roman power. Talbert collects an impressive range of examples which demonstrate the intimate connections between representing the world and owning it: monumental cadastral plans recording Roman centuriation (division) of newly acquired territory, a "shape" or "outline" (forma in Latin) of Sardinia dedicated in commemoration of the island's subjugation, the enormous marble plan of Rome known as the Forma Urbis Romae, and even a "picture of the world" (orbis depictus) placed in a rhetorical school in Augustodunum (modern Autun, France). To these monumental and ideologically-charged maps, Talbert seeks to add two examples about whose context we know considerably less, the map of Agrippa and the Peutinger Map. Although no trace of Agrippa's map survives, it is described by Pliny the Elder as containing "the lands of the globe for the city to look at" (orbis terrarum urbi spectandus). Such language, which suggests a connection between empire and cartography, is consistent with a map, but it does not entirely rule out an equally monumental textual inscription along the lines of Augustus' own Res Gestae. In the case of the Peutinger, a medieval copy of what is likely a fourth-century CE original, Talbert presents an abbreviated version of the argument advanced in his 2010 volume, Rome's World: The Peutinger Map Reconsidered (Cambridge). His close analysis of the artifact allows him to show that Roman ideology is reflected in the map's most basic features, such as its choice of center (Rome), its extent (from Britain to India), and its variable scale (Italy is depicted larger and in greater detail than anywhere else). More controversial, however, is his suggestion that the map was originally a monumental display piece, which may have hung as part of a globe image in an apse behind the emperor's throne. Talbert is the world's leading expert on the Peutinger Map and he is right to demand a sophisticated analysis that does justice both to the artifact and to its intellectual context, but his account would have also benefited from some consideration of the possibility that it was originally drawn on papyrus. This possibility, already suggested by its long, thin shape and the way its artist distorted the map to fit such a constricted medium, receives further support from the recently discovered Artemidorus Papyrus, which appears to use a similar iconography for depicting settlements, topographical features, roads, and waterways. Taken together, the artifacts' shared visual language for cartographic description may, in fact, reflect another genre of maps not for public display.

The final chapter turns from Roman artifacts to Roman texts. In "Putting the World in Order: Mapping in Roman Texts," Benet Salway considers the textual cartography of documentary, epigraphic, and literary sources. This chapter begins from the observation that texts impose a specific order on the way that geography is to be read. Salway's contribution, which is divided topically rather than generically, reacts against the scholarly trend to "downplay the role of graphic illustration in the description of geographic information by the Romans” (193). By examining the organization of itineraries, the mapping of continents, and the ordering of tribes, legions, and Roman provinces, Salway argues that "there is some circumstantial evidence for familiarity with cartographic images, either in informing the organization of the material or for facilitating its comprehension" (230). His argument is a persuasive one, based on close reading of documentary and inscriptional evidence, which could be further extended to even more literary texts, such as Roman poets (many of whom show a great deal of interest in geography), orators, and authors of prose fiction.

In light of this volume's admirably broad coverage in limited space, it is perhaps unfair to lament what it is missing. Nonetheless, I think that many readers would appreciate more explicit connections between mapping traditions across cultures, especially given the emphasis placed in the Introduction on the interrelatedness of Greco-Roman, Mesopotamian, and Egyptian mapping. Cross-references between entries tend to be superficial, with each chapter 
appearing to have been developed independently. Some atomization is to be expected given the diversity of fields represented in this volume, but there seem to have been several missed opportunities for fruitful connections (e.g., between the Book of the Fayum and Salway's contribution or between the Turin Papyrus and the Peutinger Map).

The most regrettable absence, in terms of coverage, is the Artemidorus Papyrus. Although it is mentioned twice (7; 106n.4), it never receives any serious consideration. In addition to its importance as an example of Greco-Roman cartography, it might also have helped to connect several authors' contributions. The papyrus was first widely publicized in 2006 and was subsequently published in full in 2008. Its front contains an unfinished map of an unidentified territory, excerpts from geographical texts including the work of the Greek geographer Artemidorus, and remarkably realistic sketches of human faces, hands, and feet. The back features a menagerie of some forty sketches of exotic animals, many of which are accompanied by
Greek labels. Although a vocal minority of scholars initially claimed the papyrus to be a fake, a series of articles in 2009 have led most scholars to accept it as a genuine artifact. As such, it provides important evidence for GrecoRoman cartographic practices, and I have no doubt that the combined expertise of the contributors to this volume could have made significant and timely interventions in the scholarly discussion about it.

Ancient Perspectives is a very welcome addition to an exciting and rapidly growing field in the study of the ancient Mediterranean. Talbert and his fellow contributors have brought together into a single volume a sweeping analysis of the mapping traditions of the ancient Mediterranean and Near East, which as a whole makes a powerful argument for the pervasiveness of ancient cartographic practice and the importance of studying the ancient Mediterranean and the Near East together. For specialists and non-specialists alike, this book will be an important reference and a catalyst for further research on this important topic.

\section{MAPPING LATIN AMERICA: A CARTOGRAPHIC READER}

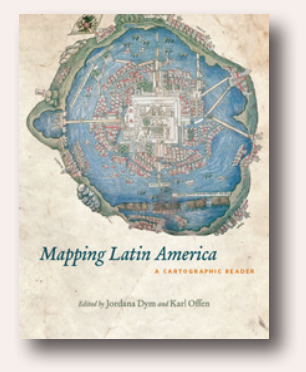

Edited by Jordana Dym and Karl Offen.

University of Chicago Press, 2011.

360 pages, 118 color plates, 12 halftones, 1 line drawing. \$40.00, paperback.

ISBN: 978-0-226-61822-7

Review by: Judith Tyner, Professor Emerita, California State University Long Beach

Although Mapping Latin America would appear, from the title, to be a history of Latin American cartography, it is much more. As the subtitle indicates, the book is a reading of various maps throughout the history of Latin America. They are used not to simply illustrate a place or time period, but are "read" for their meaning and significance to the time.

The book is organized chronologically with three major sections: Colonial, Nineteenth Century, and Twentieth Century. Each of those sections is divided into thematic subsections that deal with particular map types. The editors, Karl Offen and Jordana Dym, a geographer and a historian respectively, have put together a first-rate multidisciplinary team of fifty-four contributors. Some contributors come from geography, history, and Latin American Studies, as would be expected, but others are from archaeology, anthropology, city planning, economics, and environmental science. There are fifty-seven well-written articles, each of which is illustrated by at least one color map, for a total of ninety-eight maps. It is a real plus to have all of the maps in color and within the essays rather than grouped in a color signature.

In a brief but cogent foreword, Matthew Edney speaks of new views of maps and cartography, and notes that the essays in the book embody those new (since 1980) approaches to the history of cartography. He observes that the maps discussed are examined "in terms of the societies and culture in which they were made and consumed." In many older histories of cartography, the context of a map's making was generally ignored.

Regardless of whether one reads the book cover to cover or dips into subjects of particular interest, the Introduction by the editors is a must-read. It is an excellent discussion of current thinking on the study of maps. The authors note that they were frustrated with the limited use of maps in the study of Latin America, as maps were usually used 